\author{
Vitaly V. Tur \\ Minsk State Linguistic University
}

\title{
Telic features in the semantics of English nominal compounds
}

\section{Introduction}

One of the most striking features of English nominal compounds is the discrepancy between the simplicity of their syntactic structure and the considerable variety of semantic relations they may express. It is surprising that nouns combined in a phrase generate a new compositional unit the meaning of which cannot be deduced from the sum of the lexical meanings of its constituents. It is even more surprising that in most cases speakers hardly seem to have any difficulty in determining the plausible semantic functions of a compound and interpreting its compositional meaning.

So how do the constituents of a compound interact within its semantic structure? Where does an extra part of the meaning of a compound come from? What semantic rules enable speakers to recover this meaning, even though it is not given explicitly in the surface grammar?

Recent research on the semantics of compounds offers a new alternative view on the stated problems. The idea is that the meaning of a compound is not necessarily confined to the lexical meaning of its elements: the semantics of a compound may include various types of encyclopaedic and pragmatic information associated with its denotata; thus, an adequate semantic description of compounds requires consideration of this information.

In the present paper I focus on the semantic structure of English nominal compounds whose compositional meaning requires actualising telic features associated with the denotata of their constituents (their built-in function, effects they may cause, ways they can be affected and so on). The aims of the described research are, firstly, to find out the kinds of telic features of the constituents which contribute to the compositional meaning of compounds; secondly, it is to determine the semantico-syntactic types of the compounds which require actualising this kind of semantic information.

\section{Theoretical issues}

Semantics has always been "the greatest area of confusion and disagreement" (Ryder 1994: 16) within the framework of the study of English noun-noun compounds. Although a lot of research has been done on finding ways to describe the meaning of English compounds (Jespersen 1909, Bloomfield 1933, Hatcher 1960, Marchand 1969, Lees 1963, Brekle 1970, Gleitman and Gleitman 1970, Adams 1973, Downing 1975, Bauer 1978, Levi 1978, Warren 1978, Selkirk 1982, Hacken 1992, 1994, 2000, 2004, Ryder 1994, Coulson 2000, Booij 2005, 2010, Benczes 2006, Heinz 2009, Lieber 2009, Jackendoff 2010), the semantic nature of compounding is still far from being fully explained.

The earliest studies on the semantics of compounds were done within the generativist framework (Lees 1963, Bauer 1978, Levi 1978, Warren 1978 and others). It was argued that semantic relations between the elements of nominal compounds were formed on the bases of implicit predicates in their deep structure, which were deleted on the surface but could be 
reconstituted by transformational procedures (dust ball = ball made of dust (Warren 1987: 113)).

However, in spite of all the advantages of the generativist approach, it suffered from a number of serious drawbacks. Firstly, one and the same compound could imply various predicates (consider Ryder's example of dirt-machine, which can imply about ten different predicates: grind, pick up, move, suck up, produce, work with and so on (Ryder 1994: 435). Secondly, the recovered predicates were in most cases too abstract and vague to convey the exact meaning of the compounds. Thus, for example, S. Coulson points out that the compounds fertility pills and headache pills, which according to Levy's model both entail the predicate FOR (Levi 1978), have significant difference in their meaning: pills to increase fertility, pills to reduce headache (Coulson 2000).

The problems of the generativist approach have shown that the interpretation of the meaning of a compound cannot be realised only by determining the semantico-syntactic relations between its constituents, but also presupposes some 'world knowledge' associated with them; thus, the explanatory power of any semantic theory would depend on its ability to account for it.

One of the first attempts to formalise this knowledge was taken by L. Bauer. In Bauer's view, the meaning of a compound can be specified by the semantic description of its constituents (for example, the meaning of wind contains 'force' which helps us to interpret windmill as 'a mill powered by wind' (Bauer 1979: 48)).

E.S. Kubryakova develops the idea of semantic description of the elements of compounds, and argues that it is not the recovering of the implicit predicate that lies in the nature of the interpretation of a compound but rather the interaction of some parts of the meaning (units of information) of its constituents which are selectively actualised in the process of compounding (Kubryakova 2002: 22). To illustrate the idea E.S. Kubryakova brings the example of the Russian compounds lesnaja polyana 'forest meadow', lesnye materialy 'forest product', lesnoe hozyajstvo 'forest industry'. She points out that different parts of the meaning of the modifier forest are actualised depending on the meaning of the head noun it is combined with. Thus, forest in forest meadow actualises the information about its territory with no trees on it; in forest product, vice versa, the knowledge about trees is relevant while the information about the territory is reduced; comprehension of forest industry presupposes actualising implicit information about the role of the forest in human life and so on. The same idea is also expressed by Z.A. Kharitonchik. Consider her examples of the Russian word combinations vishnevyj sad 'cherry garden', vishnevoe platje 'cherry dress', vishnevoe varenje 'cherry jam', where different pieces of semantic information are profiled from the meaning of the modifier (Kharitonchik 2004: 275).

One the most recent attempts to combine the semantic analysis of the compounds with the semantic analysis of their constituents has been made by R. Jackendoff. The author considers the tranformationalist approach misguided. He claims that "compounding is only barely syntactic" (Jackendoff 2009: 115) and the semantic function of the compound is profiled from inside the meanings of its constituents (Jackendoff 2009: 122). R. Jackendoff focuses on different aspects of the compound meaning that come from the semantics of constituents, underlining the role of the principle of co-composition in the process of compounding.

In his study R. Jackendoff dwells on the aspects of the meaning of the constituents that become relevant in the process of generating the complex meaning of a compound. Thus, comparing helicopter attack and attack helicopter, he points out that in the latter case the modifier serves as an explication of a proper function of helicopter being the essential part 
of its lexical meaning. The notion of proper function is very close to J. Pustejovsky's telic function in the qualia-structure of the meaning of nouns (Pustejovsky 1991), both used to formalise the process of lexical combinability.

The suggested approach to the nature of compounding, which focuses on how the meaning of two nouns contributes to the meaning of the word combination, offers the challenge for further research within the framework of the semantics of compounds. This approach has been chosen as a theoretical background for the semantic research of the compounds described in the present article. In this paper I will focus on the regularities of actualising telic features in the semantic structure of the constituents of English noun-noun compounds.

Pustejovsky's notion of telic features seems appropriate here because, unlike proper function, it can be applied not only to the class of artifacts and parts of organisms but to a wider range of objects. Following J. Pustejovsky, by the terms telic features or telic role I mean any type of semantic information in a lexeme about the denotatum that specifies the ways it can function or typically be affected, the knowledge about its proper function, the purposes it may have in performing an act, and so on. In other words, the telic role is a complex of qualities in the semantic structure of a substantive that in most cases allows it to be used in the role of the performer (causer) or the addressee of the action in the propositional structure of a compound. Thus, as can be seen from the definition, the difference between the notions of telic role and proper function is that the former serves as an umbrella term which includes the latter as an individual case among other possible functions.

The study involved the semantic analysis of 4000 nominal compounds. The methodological basis of the research that helped to formalise the analysis is the introduction of the semantics of nominals in terms of Qualia-structure, suggested by J. Pustejovsky. Qualia-structure is a set of four main classes of properties and qualities (roles) associated with a given lexical item: constitutive role (the relation between an object and its constituents, or proper parts), formal role (distinguishes an object within a larger domain: its orientation, magnitude, shape, etc.), telic role (purpose and function of the object, the ways it can act or be affected, etc.), and agentive role (factors involved in the origin of the object). Thus, for example, the Qualia-structure of the lexemes novel and dictionary is presented in the following way:

Novel

\section{Const: narrative}

Form: book/disk

Telic: read

Agentive: artifact, write

Dictionary

Const: alphabetized-listing

Form: book/disk

Telic: reference

Agentive: artifact, compile (Pustejovsky 1991: 427)

According to Pustejovsky's conception, the realization of any role is possible in the process of the generation of different complex units, including the generation of nominal 
compounds. As can be seen from the examples below, the semantic variations of a modifier can be analysed according to what qualia is realised in a given compound:

\section{1) hand palm \\ 2) hand tattoo \\ 3) hand lotion \\ 4) hand control.}

Thus, in (1) it is the constitutive role of the lexeme hand which is relevant; in (2) it is the formal role (location). (3) and (4) presuppose actualisation of different telic functions of the modifier (to be used for grasping, holding; to be cared for, etc.).

The results of my research show that the telic role is actualized in about $40 \%$ of all the nominal compounds examined, either in one of their components or in both of them. Among these are the compounds with various semantico-syntactic relations, each of them described separately further in the article.

\subsection{Actor - action/result}

The semantic interpretation of the compounds under analysis presents a number of problems which haven't been solved in the framework of the transpositionalist approach. One of the problems can be illustrated by comparing the examples in (1):

1. a. teakettle whistling

b. wind whistles

c. bird whistles

d. wheel whistling

Despite the fact that the head-nouns in all the compounds in (1) name one and the same action, its agents specify its meaning, which can be possible only on condition that the semantic structure of the words teakettle, bird, wind, wheel initially possess mental schemata of the named action. It suggests the idea that a head noun does not denote whatever action can be "mechanically" applied to the agent of the proposition, but rather serves as an explication of its inherent telic function.

Note also that the process of whistling presents completely different types of activity for different agents in (1). Thus, for (1a), (1c) it is the realisation of the proper functions of an artifact and a living being. However, in (1d) whistling is not something that the artifact is designed to perform (consider some more examples of this kind: factory poison, cigar ashes, fridge noise, boot tracks). In cases like these the head noun expresses a side action (result) of the modifier which is performed alongside the realisation of its proper function.

For a more complex case, consider the elliptical constructions in (2):

2. a. meteoric risk

b. parental advice

c. fan letters

d. frost damage

Semantic interpretation of the compounds in (2) requires recovering not only the deleted predicate but also the rest of the propositional structure with its implicit arguments: meteoric risk=risk of hitting the Earth, parental advice $=$ advice to children, fan letters $=$ letters to the object of worship, frost damage=damage to an object that can be affected by low temperatures. Thus, not only the information about the possible functions of an actor but also 
about the objects which can be affected by it becomes relevant in the process of compounding.

Another semantic problem to be considered here can be illustrated by the examples in (3) and (4):

3. a. tree trunk water conducting function

b. tree trunk function was to bridge the chasm and the head of the top

4. a. presidential directive that could change the world

b. rumors of presidential divorce flood France

In (3a) and (4a) the compositional principles are clear as the heads water conducting function and directive express the proper functions of tree trunk and president. But what about (3b) and (4b)? Obviously, the functions here cannot be considered the proper ones for the named agents. Neither can they be considered their side functions, because divorce and the process of being used as a bridge have nothing to do with performing the proper duties of the president and the functions of the part of a living organism whatsoever.

It seems that to interpret such combinations one must bear in mind that one and the same object may simultaneously belong to several taxonomic groups of different levels of abstraction. As a result it may involve several families of telic functions typical of different taxonomic categories. Thus, for instance, the semantic structure of the lexeme president includes the information about the proper functions of the specific post/position (presidential decision, presidential duties), the proper functions of the president as a kind of employment in general (presidential retirement), the functions of a human-being in general (presidential hobbies, presidential divorce). Consider some more examples of this kind: elephant games (animal) - elephant shade (physical object), ambassadorial duties (position) - ambassadorial suicide (human).

Thus, the determination of the relations in the semantic structure of English "actor action/result" compounds requires the following information about the actor expressed by the modifier: 1) the set of taxonomic categories it belongs to, 2) the set of the proper functions of the actor (as a potential member of different taxonomic categories), 3) the set of its side functions, 4) possible effects it may have on other objects (as potential implicit arguments in the propositional structure of a compound). Here is a list of the semantic models for English "actor - action/result" compounds in which all of the mentioned aspects of meaning of their constituents are taken into account:

1) artifact performs the proper function/result (bullet wounds, torch lights, ferry expedition, taxi ride);

2) artifact performs a side action/result (car exhaust, cigarette ash, boot tracks, fridge noise).

3) artifact fails to perform its proper function (boiler explosion, car accident, plane tragedy);

4) human occupation - realisation of the proper function (officer directing operations, detective operations, police investigation);

5) human occupation - failure of the proper function (driver error);

6) natural object performs the proper function/has an effect on other objects (volcanic eruption, volcanic risk, meteoric risk);

7) parts of organisms perform the proper function (hand motions, heart beat); 
8) living-being performs the proper function (result)/has an effect on other objects (spider silk, bee pollination, germ disease, locust damage);

9) natural phenomenon performs the proper function/has an effect on other objects (wind whistles, snow damage).

10) physical object performs the proper function (tree trunk barricades, lime shade).

\subsection{Actor - affected object}

According to the data of the research, the "actor - affected object" type of compound is much less frequent in the corpus. In all the examples the head-noun names an artifact, so the only type of semantic relations that can be expressed within the pattern can be defined in the following way: "the artifact which is expressed by N2 is designed in such a way that the performance of its proper function presupposes the assistance of the function of N1".

Here are the examples from my corpus: horse carriages, steam organ, atom lamp, water mill, gasoline engine, gas turbine, turbine engine.

\subsection{Affected object/result - actor}

Although the tranformationalist approach enabled the singling out of the "affected object actor" pattern, it failed to notice significant semantic distinctions between the compounds that comply with it. S. Coulson's example that has been mentioned above (fertility pills headache pills) is just one of many that can be given here to show the diversity of possible semantic relations within the pattern, but before I dwell on the meaning of the compounds as a whole let me focus on the meaning of their constituents.

The head-nouns of most of the "affected object - actor" compounds in my corpus denote either artifacts or human occupations. The semantic structure of these compounds is such that the object denoted by the head-noun realises its proper function upon the object named by the modifier: heat shield (the proper function of shield is to provide protection against something), fly trap (one of the proper functions of trap is to catch somebody or something).

In a fair number of examples, however, the proper function of the head-noun is unclear due to the general meaning of the lexeme. In this case the telic function of the modifier enables us to determine the possible types of the semantic relations between the constituents: camera man (the proper function of camera is to be used for shooting; thus, man performs the role of an actor that utilizes this function). In most such cases, however, the meaning of the compound is ambiguous (or promiscuous (Jackendoff 2009: 117)). Consider, for instance, the compound hen-girl that, according to E. Ryder, may express about ten different relations: a girl who 1) lives on a farm, 2) tends to hens, 3) takes care of hens, 4) raises hens, 5) works with hens, 6) picks up the hen's eggs each morning and so on (Ryder 1994: 476).

Thus, the number of relations in the semantic structure of the "affected object - actor" compounds will depend on the number of possible effects the head-noun may have upon the modifier performing its proper function. Surprisingly, the variety of these effects does not appear wild, so they can be grouped into a fairly small number of classes. Before I give a list of possible relations consider the following examples in (5) and (6):

5. a. eye glasses

b. sun glasses

c. eye pencil 
(5a) can be traditionally transformed into "glasses for eyes" and thus can be assigned an abstract meaning of purpose. In this case no difference will become evident between (5a), (5b) and (5c) as they all comply with the same "purpose"-pattern. In fact, however, the difference is that in (5a) the proper function of glasses is to assist the proper function of eyes, in (5b) it is to resist the proper function of sun, while in $(5 \mathrm{c})$ the proper function of pencil has nothing to do with the proper function of eyes: it is to enhance its formal properties (here: outer look).

6. a. rocket pilot

b. rocket test

(6) presents different types of relations in comparison with those in (5). Here N2 does not influence the proper function of $\mathrm{N} 1$ but exploits (6a) or obtains information about its performance $(6 b)$.

In Table 1 the full list of the patterns is given that the compounds in my corpus comply with. (Reminder: $X$ stands for the meaning of $\mathrm{N}_{1}, \mathrm{Y}$ is for the meaning of $\mathrm{N}_{2}$ )

Table 1. Types of semantic relations in the "affected object - actor" compounds.

\begin{tabular}{|c|c|c|c|}
\hline $\begin{array}{l}\text { Properties of N1 } \\
\text { affected }\end{array}$ & Type of effect & $\begin{array}{l}\text { Frequency } \\
\text { of } \\
\text { occurrence }\end{array}$ & Examples \\
\hline \multicolumn{4}{|l|}{$\begin{array}{l}\text { Effect upon telic } \\
\text { functions }\end{array}$} \\
\hline & $\begin{array}{l}Y \text { resists a telic function } \\
\text { of } X\end{array}$ & $14.7 \%$ & $\begin{array}{l}\text { lightning rod, shock gear, heat } \\
\text { shield }\end{array}$ \\
\hline & $\begin{array}{l}Y \text { assists a telic function } \\
\text { of } \mathrm{X}\end{array}$ & $13.8 \%$ & $\begin{array}{l}\text { eye glasses, liver pills, engine } \\
\text { oil }\end{array}$ \\
\hline & $\begin{array}{l}\text { Y exploits a telic function } \\
\text { of } X\end{array}$ & $12.7 \%$ & camera man, rocket pilots \\
\hline & $\begin{array}{l}Y \text { obtains information } \\
\text { about the performance of } \\
\text { a telic function of } X\end{array}$ & $4 \%$ & rocket tests, traffic camera \\
\hline & $\begin{array}{l}\text { Y controls a telic function } \\
\text { of } X\end{array}$ & $1 \%$ & animal charmer \\
\hline \multicolumn{4}{|l|}{$\begin{array}{l}\text { Effect upon } \\
\text { physical } \\
\text { properties }\end{array}$} \\
\hline & Y moves $\mathrm{X}$ in space & $9.8 \%$ & $\begin{array}{l}\text { hay truck, barge pole (a pole } \\
\text { used to guide a barge) }\end{array}$ \\
\hline & $\begin{array}{l}\text { Y changes physical } \\
\text { properties of X }\end{array}$ & $8 \%$ & $\begin{array}{l}\text { hand lotion, floor varnish, } \\
\text { dish towel, food coolers }\end{array}$ \\
\hline & $\begin{array}{l}\text { Y obtains information } \\
\text { about the physical } \\
\text { properties of } X\end{array}$ & $1 \%$ & $\begin{array}{l}\text { eclipse observer, distance } \\
\text { meter }\end{array}$ \\
\hline
\end{tabular}




\begin{tabular}{|l|l|l|l|}
\hline $\begin{array}{l}\text { Effect upon } \\
\text { constitutive } \\
\text { properties }\end{array}$ & & & \\
\hline & $\begin{array}{l}\text { Y changes } \\
\text { structure/contents of X }\end{array}$ & $1 \%$ & book editor, meat chopper \\
\hline $\begin{array}{l}\text { Effect upon } \\
\text { agentive } \\
\text { properties }\end{array}$ & & & \\
\hline & Y creates/causes X & $20 \%$ & $\begin{array}{l}\text { credit deal, shed wall, song } \\
\text { birds, cartoon man }\end{array}$ \\
\hline & Y obtains X & $10 \%$ & tourist trap, truth drug \\
\hline & Y destroys/annihilates X & $4 \%$ & pain pills, fire extinguisher \\
\hline
\end{tabular}

Thus, in spite of the wide lexical variety of the constituents of the "affected object actor" compounds, their compositional meanings fall into a relatively narrow range of semantic functions; these functions are determined by the types of effect the actor (denoted by N2) may have on the properties of the affected object (N1).

\subsection{Place/time-object}

According to the survey results, telic role can also be actualized in the meaning of the components of locative compounds. Thus, when analyzing the meaning of the compounds (7) village street, (8) village doctor, (9) village boy it becomes evident that although all of them are traditionally considered locative, only (7) can be transformed into " $\mathrm{Y}$ is in $\mathrm{X} »$. The objects denoted by the head nouns of the compounds (8) and (9) do not presuppose their immediate location in the place named by the modifier, and are connected to them by means of their proper functions: "doctor works in a village", "boy lives/grew up in a village".

"Place/time-object" compounds, in which the head noun actualizes its telic role, can be grouped according to the type of actualised telic function (see Table 2).

Table 2. Types of compositional meaning in "place/time-object" nominal compounds.

\begin{tabular}{|l|l|l|}
\hline Semantic relations & $\begin{array}{l}\text { Frequency of } \\
\text { occurrence }\end{array}$ & Examples \\
\hline $\begin{array}{l}\text { Y performs its proper } \\
\text { function in/on X }\end{array}$ & $66.3 \%$ & $\begin{array}{l}\text { town cop, surface } \\
\text { robot, bedroom } \\
\text { slippers, army knife }\end{array}$ \\
\hline $\begin{array}{l}\text { Y performs its proper } \\
\text { function during X }\end{array}$ & $18.8 \%$ & $\begin{array}{l}\text { afternoon crew, night } \\
\text { watchman, summer } \\
\text { lightning, night } \\
\text { cream, summer } \\
\text { clothes }\end{array}$ \\
\hline $\begin{array}{l}\text { Y's telic function is to be } \\
\text { placed is kept/placed in } \\
\text { X }\end{array}$ & $5.7 \%$ & $\begin{array}{l}\text { pocket paraphernalia, } \\
\text { wall holder, ear ring, } \\
\text { fridge magnets }\end{array}$ \\
\hline
\end{tabular}




\begin{tabular}{|l|l|l|}
\hline $\begin{array}{l}\text { Y's telic function is to } \\
\text { move through/to/from X }\end{array}$ & $\begin{array}{l}\text { air travelers, star } \\
\text { pilot, ocean racers, } \\
\text { ocean wind }\end{array}$ \\
\hline
\end{tabular}

As can be seen from the table above the most frequent are compounds in which the modifier denotes the place or time of functioning of the object named by the head noun (70.8\%); the head nouns in these compounds are expressed in most cases by a noun denoting either an artifact or a human-being by his/her profession or social function $(90 \%$ of all the cases).

The following semantic models belong to the pattern:

1) populated area (telic: human habitat) - human (telic: social function/work): town cop, village priest, farmhouse servants, county sheriff, state police, room steward, planet police, etc.

2) organizations/institutions/enterprises/establishments (telic: proper function) - human (telic: social function/work): hospital director, college boy, school teacher, bank president, prison doctor, army guys, library steward, etc.

3) organizations/institutions/enterprises/establishments/parts of buildings (telic: proper function) - human-made object (telic: proper function): bedroom slippers, hospital bathrobe, bar stool, kitchen table, hospital gown, home uniform, etc.

4) other areas, regions, places, surfaces - human (telic: perform a social function/work): riverboat gambler, space miner, tightrope walker, etc.

5) other areas, regions, places, surfaces (telic: placement/container) - human-made object (telic: proper function): area bell, lawn chair, street sign, space boots, air apparatus, mattress topper, surface robot, etc.

6) time - human-made object (telic: proper function): night cream, night clubs, summer cottage, evening clothes, spring dresses, etc.

7) time - human (telic: perform a social function/work): night watchman, afternoon milkman, afternoon crew, morning viewers, summer friend, childhood friends, holiday mates, etc.

\subsection{Object - place}

The group of "object-place" compounds expresses the types of complex meaning that are listed below (see Table 3). The table shows that the compounds in which the head noun denotes a container for storing the objects named by the modifier amount to more than a half of all compounds of this type.

Table 3. Types of compositional meaning in "object-place" nominal compounds.

\begin{tabular}{|l|l|l|}
\hline Semantic relations & $\begin{array}{l}\text { Frequency of } \\
\text { occurrence }\end{array}$ & Examples \\
\hline $\begin{array}{l}\text { Y's proper function is to } \\
\text { serve as a container for X }\end{array}$ & $64 \%$ & $\begin{array}{l}\text { garbage cans, laundry } \\
\text { basket, oil tanks, }\end{array}$ \\
\hline
\end{tabular}




\begin{tabular}{|l|l|l|}
\hline & & kitchen utensil drawer \\
\hline $\begin{array}{l}\text { Y's proper function is to } \\
\text { serve as a place where X } \\
\text { performs its proper } \\
\text { function }\end{array}$ & $24 \%$ & $\begin{array}{l}\text { cook unit, pilot } \\
\text { boards, engine rooms, } \\
\text { computer club }\end{array}$ \\
\hline $\begin{array}{l}\text { Y's proper function is to } \\
\text { serve as a } \\
\text { placement/aperture for X }\end{array}$ & $12 \%$ & $\begin{array}{l}\text { coin slot, signature } \\
\text { line, idea notebook, } \\
\text { bolt holes }\end{array}$ \\
\hline
\end{tabular}

\subsection{Proper function - object}

A specific place among the semantic types of compounds under analysis is held by the compounds in which a deverbal modifier names the function for the performance of which the denotatum of the head noun is designed.

holding pins, replacement ferry, fishing vessels, cleaning equipment, warning sign, control button, service personnel, care nurse, research teams, cruise liner, nursing home, operating theater

The meaning of such compounds can be described by the transformation «Y's proper function is to perform $\mathrm{X} »$. The compounds under analysis can be divided into subtypes in accordance with the semantics of the head-noun:

1) proper function - artifact: development money, sewing machine, closing shutters, heating system, test program, irrigation canals, intake pipe, protection stunner, etc.

2) proper function - place (buildings, part of buildings, natural and artificial areas used as a place of performing the action): dance floor, swimming pool, skating rink, service area, reading chair, examination table, launch site, killing zone, rest area, farming settlement, amusement hall, etc.

3) proper function - human/group of people (proper function of professions/occupations): ski team, survey teams, airshow performers, rescue party, etc.

\section{Conclusion}

The semantics of a complex lexical unit is the result of the interaction of the meaning of its constituents. In most cases, however, it is not enough to account for the lexical meaning of the constituents as a whole in order to interpret the semantics of a compound. The meaning of a compound results from the interaction of some particular units of information associated with its constitutive elements.

Telic role, which is an integral part of the meaning of nouns, appears to be semantically relevant to almost $40 \%$ of all examined compounds, being actualized either in 
one of its elements or in both of them. It has been shown that telic role is a general notion which consists of different kinds of semantic information. Among them is the information about 1) the proper function of a denoted object, 2) its side functions that can be realized alongside the performance of the proper one, 3) a set of objects that may be affected by it, 4) types of the effect it may have on other objects, 5) a set of objects that may have an effect on it 6) the ways it can be affected by other objects.

As has been demonstrated in the article, any piece of this encyclopedic ("world") knowledge about the denoted object may serve as a semantic link that helps the lexeme to combine with other words in a phrase. Thus, compositional semantics must account for this information in order to be able to explain the linguistic nature of compounding.

\section{References}

Bauer, Laurie. 1979. In the need for pragmatics in the study of nominal compounding. Journal of Pragmatics3. 45 - 50.

Coulson, Seana. 2000. Semantic Leaps: Frame-shifting and conceptual blending in meaning con-struction. Cambridge: Cambridge University Press.

Jackendoff, Ray 2009. Compounding in the parallel architecture and conceptual semantics. In: Rochelle Lieber and Pavol Stekauer (eds.), The Oxford Handbook of Compounding, 105128. Oxford University Press.

Kharitonchik, Zinaida 2004. O refleksii leksicheskih znachenij componentov v semantike affiksalnyh proizvodnyh. In: Ocherki o jazyke. Teorija nominacii. Leksicheskaja semantika. Slovoobrazovanije. Izbrannye trudy. 266 - 281. Minsk.

Kubryakova, Elena 2002 Kognitivnaja lingvistika i problemy kompozicionnoj semantiki v sfere slovoobrazovanija. Izvestija AN. Seria Literatury Jazyka 61 (1). 13-24.

Levi, Judith N. 1978. The Syntax and Semantics of Complex Nominals. New York: Academic Press.

Pustejovsky, James. 1991. The Generative Lexicon. Computational Linguistics17(4). 409441.

Ryder, Mary Ellen. 1994. Ordered Chaos: The interpretation of English noun-noun compounds. Berkeley and Los Angeles: University of California Press.

Warren, Beatrice. 1987. Semantic Patterns of Noun-Noun Compounds. Gothenburg: Gothenburg Studies in English 41. Acta Universitatis Gothoburgensis. 